\title{
Morphological and genetic diversity of two individual forms of Euphaedra eberti (Lepidoptera, Nymphalidae)
}

\author{
Milan Zúbrik', Sandrine Picq ${ }^{2}$, Philippe Oremans ${ }^{3}$, Audrey Nisole², \\ Sophie Tremblay ${ }^{2}$, Michel Cusson ${ }^{2}$, Lubomír Panigaj ${ }^{4}$, Barbora Mikitováa ${ }^{4}$, \\ Maurizio Bollino ${ }^{5}$
}

I National Forest Centre, Forest Protection Service, Lesnicka 11, 96901 Banská Štiavnica, Slovak Republic 2 Laurentian Forestry Centre, Natural Resources Canada, 1055 du P.E.P.S., P.O. Box 10380, Stn. Ste. Foy, Quebec City, G1V 4C7, Canada 3 35, rue des Jacinthes, 6110 Montigny le Tilleul, Belgium 4 Pavol Jozef Šafárik University, Šrobárova 2, Košice, Slovak Republic 5 Museo di Storia Naturale del Salento, 73021 Calimera, Italy

Corresponding author: Milan Zübrik (zubrik@nlcsk.org)

Academic editor: John Midgley | Received 8 April 2019 | Accepted 18 June 2019 | Published 17 September 2019

http://zoobank.org/24A271CD-B533-4511-ADFC-FC5C2CE96769

Citation: Zúbrik M, Picq S, Oremans P, Nisole A, Tremblay S, Cusson M, Panigaj L, Mikitová B, Bollino M (2019) Morphological and genetic diversity of two individual forms of Euphaedra eberti (Lepidoptera, Nymphalidae). African Invertebrates 60(2): 195-213. https://doi.org/10.3897/AfrInvertebr.60.35262

\begin{abstract}
A total of 385 Euphaedra eberti Aurivillius, 1898, adults collected between 2012 and 2018 in the vicinity of Bangui, Central African Republic, were examined for intraspecific morphological variability, genetic diversity and genitalia structure. The species shows significant wing pattern variability. Two main morphotypes were identified in the set: the nominate form eberti, and the one comprising specimens with a red patch, form rubromaculata. However, both forms had similar genitalic structures and shared some specific wing marks, in addition to displaying the same COI (i.e., barcode region of the mitochondrial cytochrome c oxidase subunit I gene) haplotype, strongly suggesting that the two morphologically distinct forms belong to the same species, E. eberti. The causes of this variability remain unclear.
\end{abstract}

\section{Keywords}

Limenitidinae, Euphaedra taxonomy, male and female genitalia, color variation, COI gene sequencing

Copyright Milan Zúbrik et al.This is an open access article distributed under the terms of the Creative Commons Attribution License (CC BY 4.0), which permits unrestricted use, distribution, and reproduction in any medium, provided the original author and source are credited. 


\section{Introduction}

The genus Euphaedra Hübner, 1819 (Lepidoptera, Nymphalidae), with about 200 recognized species, is one of the most speciose butterfly genera in Africa. The majority of species within this genus are true rain forest insects that live under the tree canopy. Despite the fact that these species form one of the most colorful, and one of the largest groups of butterflies on the African continent, many unresolved issues about their taxonomy persist (Hecq 1997; Berger 1981; Van de Weghe 2010). Not only are descriptions of new species often poor, information on the location of type material is regularly missing (Hecq 1982, 1997). In addition, publication of descriptions of genitalic structures has only recently begun (Pyrcz et al. 2011, 2013). According to Pyrcz et al. (2013) "the genus requires more detailed studies at the lower taxonomic level, such as species groups or subgenera, to help prepare the ground for a more broad-based revision".

Euphaedra eberti Aurivillius, 1898 (Lepidoptera, Nymphalidae) belongs to the group themis (Hecq 1976) of the subgenus Euphaedrana Hecq, 1976. Its type locality (TL) "Congogebiet: Ubangi-Fluss, Amadi" is situated in the northwestern Democratic Republic of Congo (DRC). The geographic range of E. eberti covers the central part of Equatorial Africa. It has been recorded from DRC, Central African Republic (CAR) and Uganda (Hecq 1982, 1997), but has not been found in Cameroon or Gabon (Van de Weghe 2010). It is also missing from all Western Africa (Larsen 2005). This species is generally considered uncommon all over its range.

Two subspecies of E. eberti have so far been described. Berger (1940) described Euphaedra hamus from Rutshuru (DRC) near the border with Uganda and Rwanda; later on Hecq (1982) downgraded the species to a subspecies of E. eberti. Euphaedra eberti hannoti was described more recently by Hecq (2008) from TL Luki (Bas-Congo, DRC). Both sexes of E. eberti hamus are poorly colored, while both males and females of E. eberti hannoti are quite colorful.

In 1920, Schultze described an E. eberti colorful form based on a single female collected by himself in Duna (Ubangi, Belg. Kongo, presently DRC), and with a different color pattern by comparison to the species described by Aurivillius (1896). According to Schultze's description, the specimen had a large red patch at the base of the FWR and he named this form as aberration (ab.) rubromaculata. Hecq $(1982,1997)$ reported on the existence of large intraspecific variability within $E$. eberti, but he, for unknown reasons, never mentioned ab. rubromaculata in his publications; he provided illustrations of adult females of the red-wing form, but always labeled them as E. eberti, not as ab. rubromaculata.

The two above individual forms, i.e. the nominate form E. eberti eberti, without the red patch, and the red-wing form, E. eberti ab. rubromaculata, display large differences in their wing patterns. Therefore the question may be raised as to whether they should be considered two separate species, perhaps wrongly described as a single species by earlier authors (Aurivillius 1896; Hecq 1982, 1997). Thus, the goal of the present investigation was to assess the possibility that the two color forms of E. eberti may represent distinct species. 


\section{Material and methods}

\section{Butterfly collection and identification}

The study material - adults of E. eberti - were provided by a local collector. They were collected using entomological nets and fruit-baited traps between 2012 and 2018, in an area west of the Ubangi River, south west from Bangui, in CAR. Dead adult specimens were shipped to the laboratory of Forest Research Institute Zvolen (Slovakia). The specimens were set and subsequently identified based on external morphological characters, using relevant identification keys (Hecq 1982, 1997; Berger 1981). They were mounted and photographed using a Canon Mark II camera equipped with a Canon $100 \mathrm{~mm} \mathrm{f} / 2,8 \mathrm{~L}$ macro lens, portable studio flashes and soft light box. The illustrations were processed and edited using Adobe Photoshop software, but no digital color correction was made. Abbreviations used in descriptions are FW: forewing; HW: hindwing; FWD: forewing upper side; FWV: forewing under side; HWD: hindwing upper side; HWV: hindwing under side; TL: type locality. Wingspan of adults was measured. Microscopic structures were photographed using the QuickPhoto MICRO 2.1 software and an Olympus digital camera MODEL NO. C-5060 equipped with a zoom DC GV connected to a stereomicroscope (Olympus model SZ2-ILST). Plates were prepared using Adobe Photoshop software.

\section{Collection places}

Butterflies were collected at 11 locations: Bangui: $4^{\circ} 22^{\prime} 24.0^{\prime \prime} \mathrm{N} ; 18^{\circ} 35^{\prime} 15.6^{\prime \prime} \mathrm{E}$, Maka: $4^{\circ} 16^{\prime} 58.9^{\prime \prime N}$; $18^{\circ} 28^{\prime} 42.4^{\prime \prime E}$, Mbata: $3^{\circ} 41^{\prime} 28.4^{\prime \prime N}$; $18^{\circ} 18^{\prime} 21.7^{\prime \prime E}$ Mbaiki: $3^{\circ} 50^{\prime} 32.7^{\prime \prime N}$; $17^{\circ} 59^{\prime} 37.0^{\prime \prime E}$, Moloukou: $3^{\circ} 44^{\prime} 15.2^{\prime \prime N}$; 17²3'09.3"E, Bi-

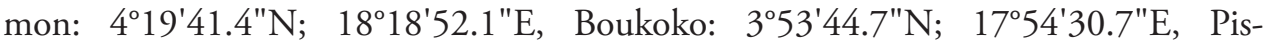
sa: $4^{\circ} 03^{\prime} 36.1^{\prime \prime N}$; $18^{\circ} 12^{\prime} 42.6^{\prime \prime} \mathrm{E}$, Bokassi: $4^{\circ} 12^{\prime} 56.3^{\prime \prime N}$; $18^{\circ} 34^{\prime} 59.8^{\circ} \mathrm{E}$, Bouchia: $3^{\circ} 45^{\prime} 41.1^{\prime \prime N}$; $18^{\circ} 10^{\prime} 48.4^{\prime \prime} \mathrm{E}$ and Mokpoto: $4^{\circ} 15^{\prime} 33.3^{\prime \prime N}$; 18³1'54.1"E.

\section{Genitalia dissection}

Male and female genitalia were dissected using standard dissection protocols (Robinson 1976). The abdomen of each specimen was severed and macerated in $10 \% \mathrm{KOH}$ for about 40 hours at room temperature, followed by removal of scales and cleaning of internal organs in distilled water, and staining of genital organs in Congo-red. Genitalic preparations were placed in microvials containing glycerol, and pinned under the mounted specimens from which they were extirpated. 


\section{DNA extraction}

For genetic analyses, we considered 32 butterflies (16 females and 16 males) of the nominate form and 32 butterflies (16 females and 16 males) of the ab. rubromaculata. DNA was extracted from one leg taken from each mounted butterfly, using the DNeasy Blood \& Tissue Kit (Qiagen, Carlsbad, CA, USA), according to the manufacturer's instructions. DNA quality was assessed using a Nanodrop ND-1000 spectrophotometer (ThermoFischer, Waltham, MA, USA).

\section{PCR amplification and COI gene sequencing}

The barcode region of the mitochondrial cytochrome $c$ oxidase subunit I (COI) gene was amplified for each butterfly using two primers: "LCO" (forward primer; 5'-GGTCAAATCATAAAGATATTGG-3') and "HCO" (reverse primer; 5'TAAACTTCAGGGTGACCAAAAAATCA-3’) (Folmer et al. 1994). All PCR amplifications were performed directly on total DNA, in a $25 \mu \mathrm{L}$ final volume, including $14 \mu \mathrm{L}$ of ultrapure distilled water, $5 \mu \mathrm{L} 5 \times$ SuperFi buffer (Invitrogen), $0.5 \mu \mathrm{L} 10 \mathrm{mM}$ dNTP mix, $2 \mu \mathrm{L} 10 \mu \mathrm{M}$ LCO/HCO primer pair, 2.25 $\mu \mathrm{L}$ DMSO and $0.25 \mu \mathrm{L}$ Platinum SuperFi DNA polymerase (Invitrogen). PCR conditions were as follows: initial denaturation step at $95^{\circ} \mathrm{C}$ for $5 \mathrm{~min}$, followed by 40 cycles of denaturing $\left(95^{\circ} \mathrm{C}\right.$, $30 \mathrm{sec})$, annealing $\left(50^{\circ} \mathrm{C}, 30 \mathrm{sec}\right)$, and extension $\left(72^{\circ} \mathrm{C}, 1 \mathrm{~min}\right)$, with a final extension step at $72{ }^{\circ} \mathrm{C}$ for $10 \mathrm{~min}$. Two $\mu \mathrm{L}$ of PCR product was then analyzed by gel electrophoresis to verify the success of amplification. PCR products were then submitted to Sanger sequencing, conducted on an ABI 3730xl sequencer (Applied Biosystem, Waltham, MA, USA). Sequencing was performed at the Genome Sequencing and Genotyping platform of the CHUL, in Quebec City (Quebec, Canada).

\section{Genetic analysis}

Sequences were aligned, read and corrected using the GeneStudio software (GeneStudio inc. 2011, http://genestudio.com/). For each individual form, we used the Mega7 software (Kumar et al. 2016) to calculate the number of variable sites, the proportion of variable sites, nucleotide diversity $(\pi)$ and genetic distances based on the TamuraNei model (Tamura and Nei 1993). Nucleotide diversity is considered a classic measure of the degree of polymorphism within a population (i.e., red and nominate forms).

In addition, we constructed a maximum likelihood (ML) phylogenetic tree, using the General time reversible (GTR) model. In constructing this tree, we included four Euphaedra outgroup species: E. zaddachi Dewitz, 1879, E. herberti Sharpe, 1891, E. eusemoides Grose-Smith \& Kirby, 1889 and E. uganda Aurivillius, 1895. These species were selected on the basis of COI sequence availability in GenBank (E. zaddachi, KU219620.1; E. herberti, AY218241.1; E. eusemoides, KU219618.1, E. hewitsoni, 
MG741027.1, E. spatiosa, MG741121.1 and E. uganda, KU219619.1). Finally, we conducted an analysis of molecular variance (AMOVA) to statistically assess whether there existed a genetic difference between the red and nominate form.

Finally, median joining networks (Bandelt et al. 1999) were computed to examine intraspecific divergence among E. eberti COI sequences, as implemented in the software POPART (Population Analysis with Reticulate Trees), using default settings. This analysis also served to examine COI haplotype distribution as a function of collection site, morph (red/nominate) and sex.

\section{Results}

\section{Notes on $E$. eberti intraspecific diversity}

A total of 385 specimens of E. eberti were analyzed during this study, and two significantly different individual forms were identified: the nominate form eberti (Figures 1,2 ) and the red-wing form identified as ab. rubromaculata (Figures 3, 4). In total, 345 (89.6\% of 385) specimens belonged to the form eberti and 40 (10.4\% of 385) belonged to the ab. rubromaculata. Among the ab. rubromaculata females, two color forms were observed, one with yellow-green color on FWD and a yellow subapical band (Figure 4) and the second one displaying a blue-yellow background on FWD and a fully white subapical band (Figure 5). The latter was particularly rare in the study material, with only 1 out of 8 red-patch specimens fitting this description.

\section{Description of adults and their genitalia}

\section{Euphaedra eberti eberti Aurivillius, 1898}

Description of males. Wingspan: $6.0-7.2 \mathrm{~cm}(\mathrm{n}=16, \overline{\mathrm{x}}=6.51 \mathrm{~cm}, \mathrm{SD}=0.31)$. The dorsal side appears metallic green (Figure 1a). Subapical band in clearly " $S$ " shape (Figure 1b), pale green or yellow green (never white). Ventral side is generally brown with green, ochre or orange shades. A basal reddish area is nearly always observed in the FWV cell and space 8 of HWV (Figure 1c), the pale yellow subapical band of FWV being also " $S$ " shaped (Figure 1d). The HWV submarginal band is well developed and clearly visible (Figure 1e). The inner part of the space 6 of the HWV is always darker (gray green) than the outer side (creamy yellow) (Figure 1f). The cells 3-5 are similarly divided into the two colored parts (inner darker and outer lighter) (Figure 1g). Spots in discal cell on HWV are scarce, only 1 or 2 (rarely 3) are present (Figure $1 \mathrm{~h}$ ).

Male genitalia (Figure 6a, b). The E. eberti eberti male genitalia copy the pattern for the genus Euphaedra, e.g., E. eshu, E. wojtusiaki, resp. E. cyparissa and E. sarcoptera (Pyrcz et al. 2011, 2013). Tegumen has the same length as uncus that is wide on base, slightly arched in distal third, with a sharp tip pointing to valvae in lateral view. Gnathos 


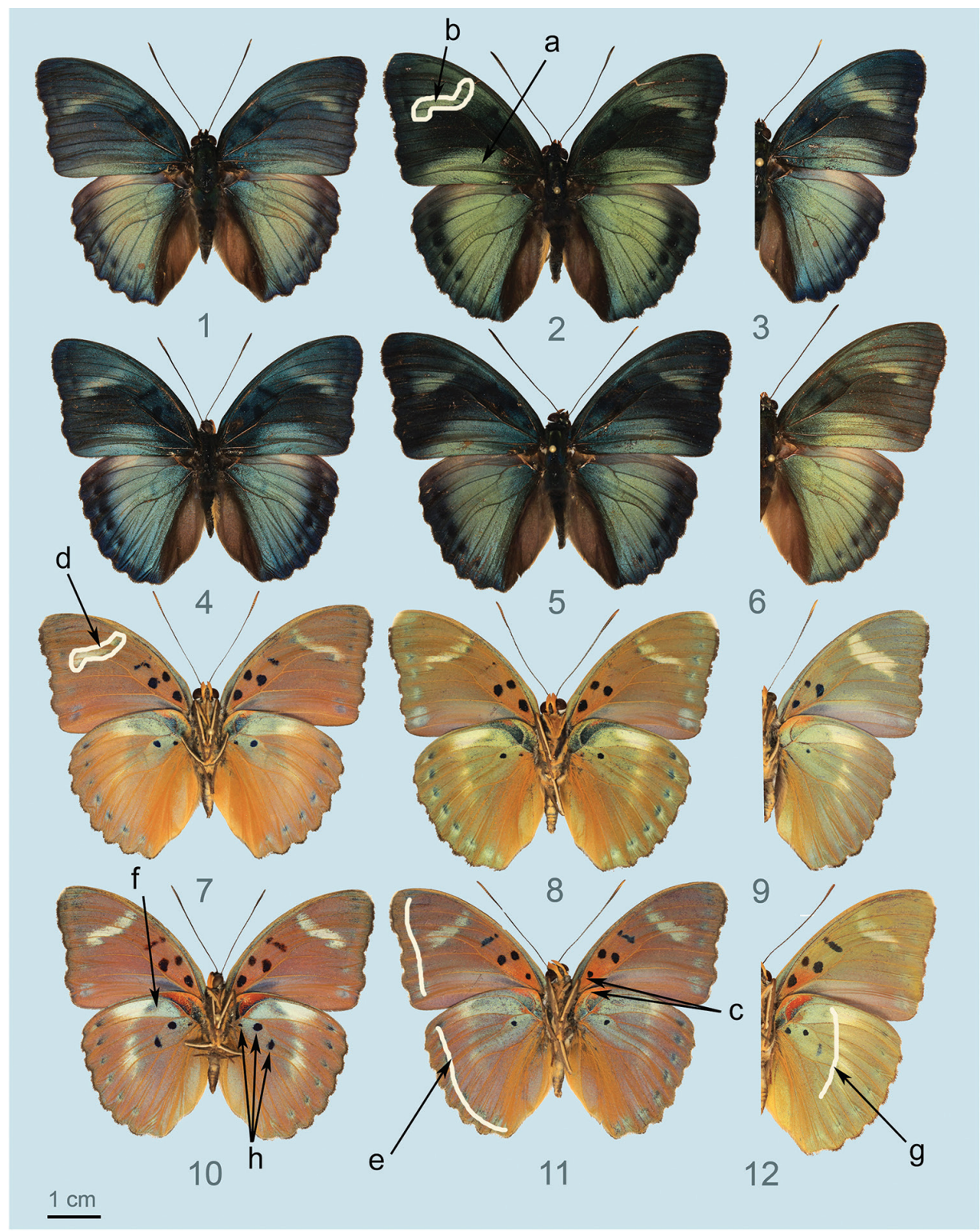

Figure I. E. eberti eberti, adults, males. 1 recto, 7 verso (Bangui; 2014); 2 recto, 8 verso (Bauchia; 14 Dec. 2016); 3 verso, 9 recto (Maka; 11. Mar. 2017); 4 recto, 10 verso (Bangui; 4 Mar. 2016); 5 recto, 11 verso (Boukoko; 20 Jun. 2015); 6 recto, 12 verso (Bimon; 8 May. 2017). Arrows point to structures referred to in the results section.

is straight and long, about the same length as uncus, saccus narrowed and with a spiny tip, slightly curved in lateral view. Valvae with simple sacculus in the middle of the valvae are smooth, oblong, slightly narrowing to the distal end, which is simple and round. At the distal end of aedeagus is a tip with semi-circularly arranged short cornuti on its base. 


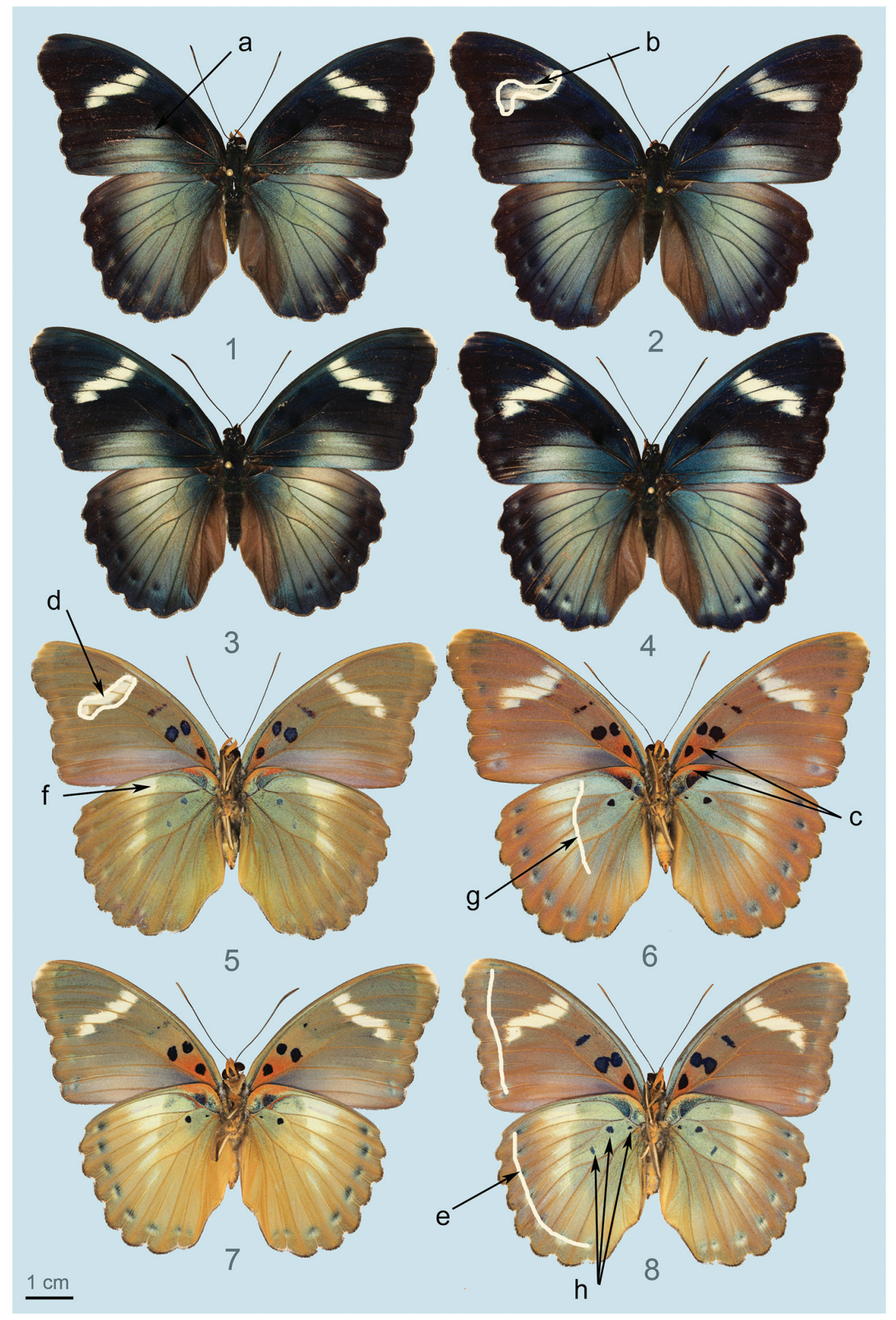

Figure 2. E. eberti eberti, adults, females. 1 Recto, 5 verso (Bangui; 17 mar. 2016); 2 Recto, 6 verso (Boukoko; 6 jun. 2016); 3 verso, 7 recto (Maka; 2014); 4 recto, 8 verso (Maka; 2014). Arrows point to structures referred to in the results section. 
Description of females. Wingspan: 7.6-9.0 $(\mathrm{n}=16, \overline{\mathrm{x}}=8.19 \mathrm{~cm}, \mathrm{SD}=0.33)$. FWD dorsal ground color black with a gray-blue-green (Figure 2a) basal area covering spaces $1 \mathrm{a}, 1 \mathrm{~b}$ and basal portion of space 2 ; white (never yellow) subapical band, "S" shaped and highly variable in size (Figure $2 \mathrm{~b}$ ). Ventral side generally brown with green, ochre or orange shades. A bit red almost always on the basal cells of both wings (Figure 2c). Subapical band on FWV in "S" shape (Figure 2d), pale yellow. HWV with submarginal spots forming clearly visible band (Figure 2e). Females show the same characteristic mark observed in males - darker inner part and lighter other side of the space 6 (Figure 2f). The spaces 3-5 show the same characteristics - inner part darker (gray-green) and outer one lighter (creamy yellow) (Figure 2g). Spots in HWV discal cell weak, in most cases being present only 1 or 2 (rarely 3) (Figure 2h).

Female genitalia (Figure 6c). Papillae anales are long and narrow, ductus bursae as long as corpus bursae oval shaped. Corpus bursae, which is longitudinally finely curled, no signum. Bursa copulatrix is broad, apophyses posteriores shorter than papili annales and extended antrum sclerotized.

\section{Euphaedra eberti ab. rubromaculata Schutze, 1920}

Description of males. Wingspan: $5.0-7.2 \mathrm{~cm}(\mathrm{n}=16, \overline{\mathrm{x}}=6.43 \mathrm{~cm}, \mathrm{SD}=0.45$, not significantly different from that of $E$. eberti eberti males). Metallic green on FWD (Figure 3a). Subapical band in "S" shape (Figure 3b), green-yellow or yellow and sometimes reduced, only spots in spaces 3 and 4 are visible. Spots in spaces 5 and 6 can be completely missing or can be very weak (Figure 3c). The basal area of FWD bears a large red patch (Figure 3d), bordered by a black line, mostly visible in space 1b, but present also in space 1a and in cell. Ventral ground color of both wings generally green and yellow with numerous black spots, and usually with red patches either in basal portion of FWV cell, and in space 7 and 8 of HWV (Figure 3e). Subapical band on FWV yellow (Figure 3f), sometimes very weak, almost missing in spaces 5 and 6, or sometimes missing almost completely; if present, it is in " $\mathrm{S}$ " shaped. Submarginal band well developed on HWV and seen clearly also on FWV (Figure 3g). Inner part of space 6 always darker (grey-green), and outer side (creamy yellow) separated by a black spot (Figure $3 \mathrm{~h}$ ). Basal, postdiscal and discal parts of the HWV always darker than the rest of the wing (Figure 3i). There is a convex line composed of 4 black spots on FWV in spaces 3, 4, 5 and 6 (Figure 3j). This line is always present and these 4 black spots are never in line with the black spot in space 2 (Figure 3k). Spots in the discal cell on the HWV are large and strongly marked, being in most cases 2 or 3 (rarely 4) (Figure 31).

Male genitalia (Figure 6d, e). Differences between E. eberti eberti and E. eberti ab. rubromaculata are minimal, most likely within intraspecific variability.

Description of females. Wingspan: 7.7-9.2 cm $(n=16, \bar{x}=8.42 \mathrm{~cm}, S D=0.40$; not significantly different from that of $E$. eberti eberti females). FWD dorsal ground color black with a yellow-green (Figure $4 \mathrm{a}$ ) basal area covering spaces $1 \mathrm{a}, 1 \mathrm{~b}$ and basal portion of space 2 . Subapical band has a poorly distinct "S" shape (Figure $4 \mathrm{~b}$ ). Borders 


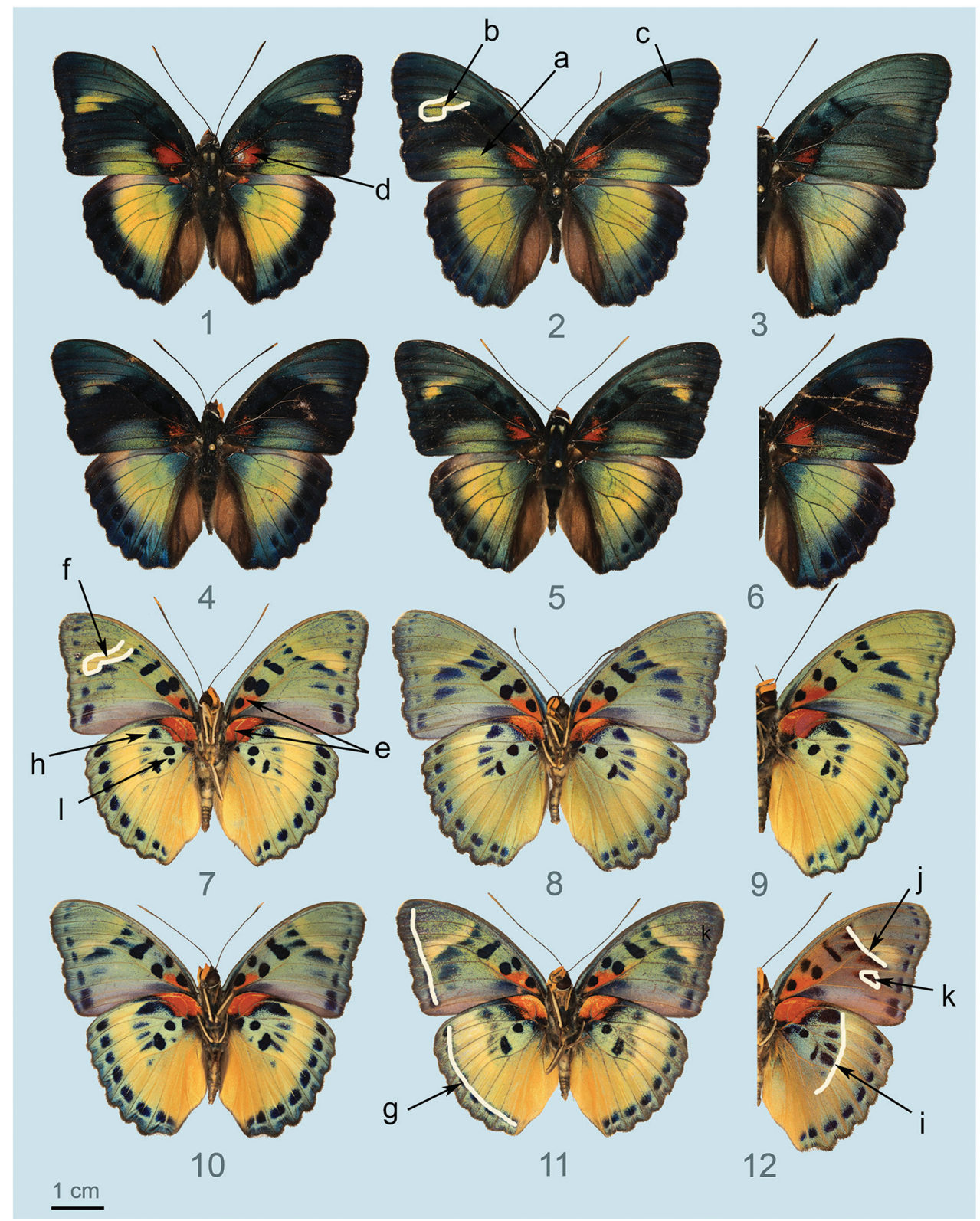

Figure 3. E. eberti ab. rubromaculata, adults, males. 1 recto, 7 verso (Mokpoto, 22 Jul. 2017); 2 recto, 8 verso (Mokpoto; 22 Jul. 2017); 3 verso, 9 recto (Bangui; 2016); 4 recto, 10 verso (Bangui; 2014); 5 recto, 11 verso (Boukoko; 9 Jun. 2018); 6 recto, 12 verso (Bokassi; 10 Jun. 2016). Arrows point to structures referred to in the results section.

of subapical band more or less parallel, with visible "teeth" on inner border, which is always present (Figure 4c). Color of subapical band always yellow, size very variable. A large red patch in the basal area of FWD (Figure 4d), bordered by a black line, mostly 


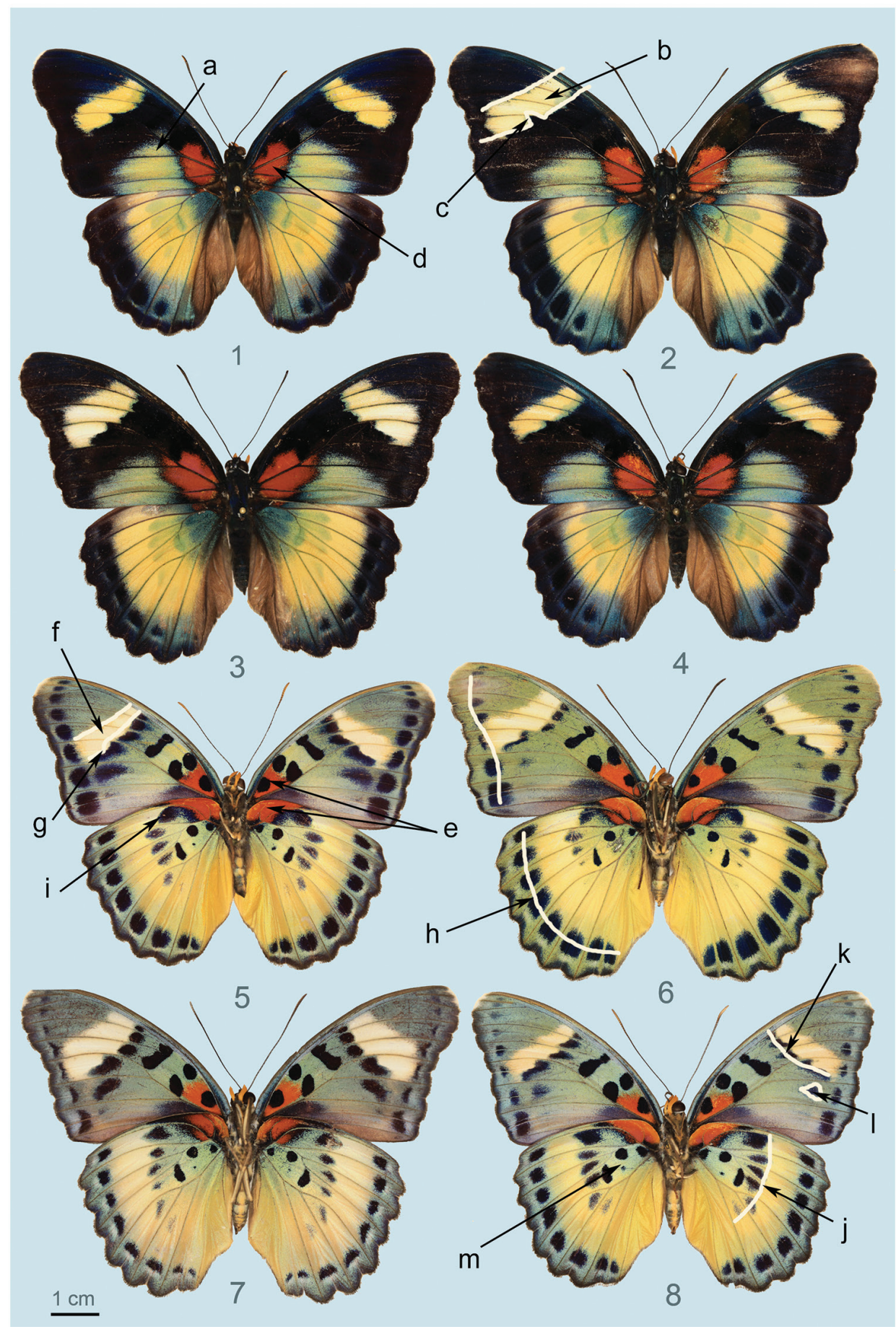

Figure 4. E. eberti ab. rubromaculata, adults, females. 1 recto, 5 verso (Mokpoto; 8 Aug. 2015); 2 recto, 6 verso (Pissa; 20 Aug. 2016); 3 verso, 7 recto (Bokassi; 22 Sep. 2016); 4 recto, 8 verso (Bangui; 2014). Arrows point to structures referred to in the results section. 


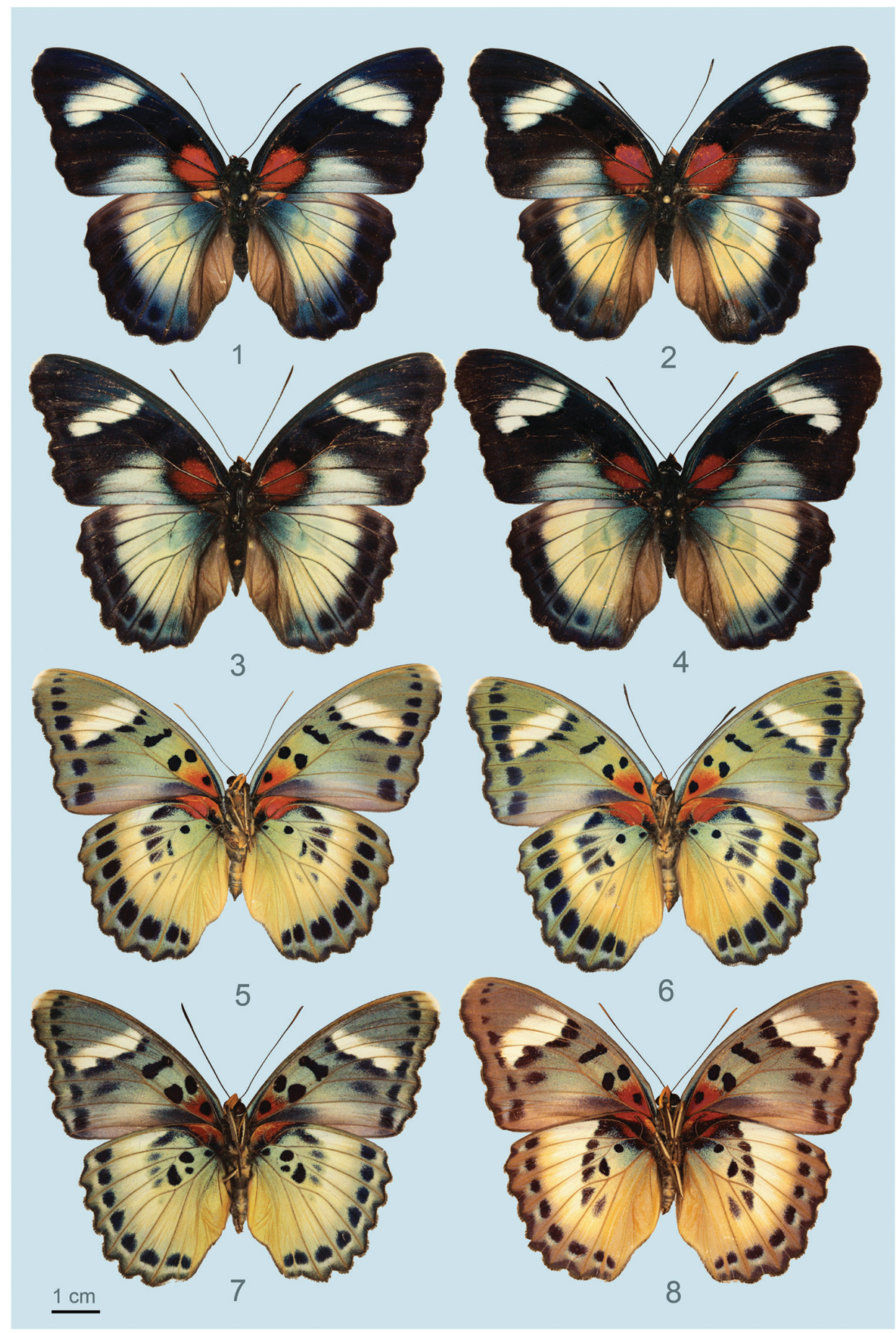

Figure 5. E. eberti blue form, adults, females. 1 recto, 5 verso (Bangui, 2015); 2 recto, 6 verso (Bangui; 2015); 3 verso, 7 recto (Mokpoto; 2016); 4 recto, 8 verso (Bokassi; 2016). 


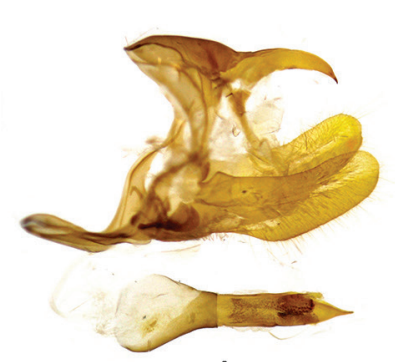

A

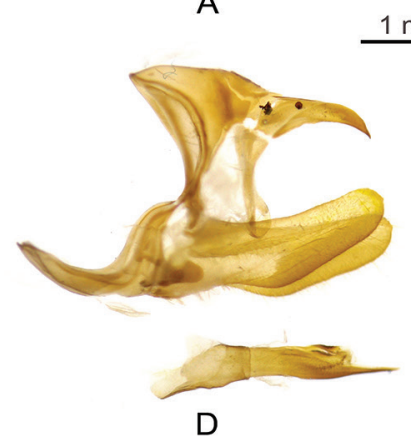

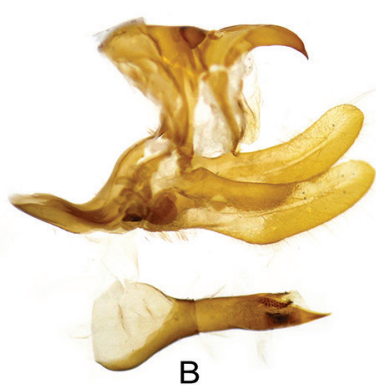

$1 \mathrm{~mm}$

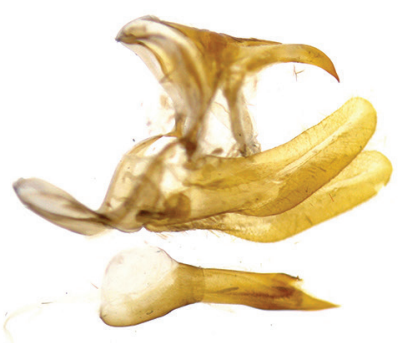

E
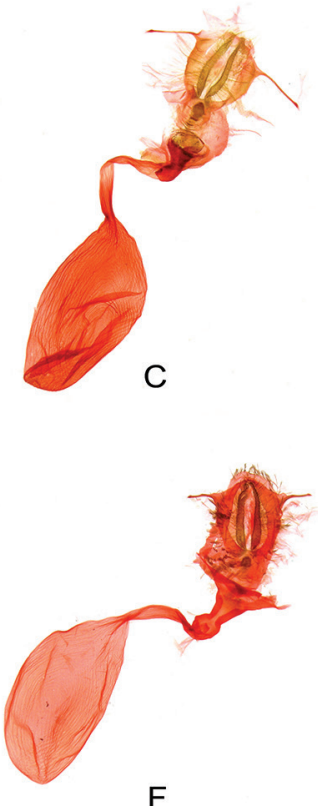

Figure 6. Genitalia in lateral view (aedeagus extracted). Two males (A, B) and one female (C) genitalia of E. eberti eberti and two males $(\mathbf{D}, \mathbf{E})$ and one female $(\mathbf{F})$ genitalia of E. eberti ab. rubromaculata.

visible in space $1 \mathrm{~b}$, but distinctly present also in space $1 \mathrm{a}$ and in cell. Ventral ground color of both wings is generally green-yellow, with many black spots, and a marked red area covering the base of both wings (Figure 4e). Subapical band creamy yellow (Figure 4f), borders almost parallel, inner border distinctly broken in space 3 (Figure 4g). Submarginal band well developed on HWV and clearly seen also on FWV (Figure 4h); consists of large, rectangular black spots. Inner part of space 6 (Figure 4i) always darker (gray-green) and outer side (creamy-yellow) separated by a black spot. Basal, postdiscal and discal parts of the HWV always darker than the rest of the wing (Figure 4j). There is a convex line of four black spots on FWV in spaces 3, 4, 5 and 6 (Figure 4k); it is always present and these 4 black spots are never in line with the black spot in space 2 (Figure 41). Some specimens (Figure 5) have all of the characteristics described above for E. eberti ab. rubromaculata females, except for the background color on FWD, which is yellow-blue, and the color of subapical band is always white on both sides.

Female genitalia (Figure 6f). No differences relative to those of E. eberti eberti are visible.

\section{COI sequencing and genetic analyses}

We successfully obtained the COI barcode sequence (572 nucleotides) for 47 specimens ( 25 red and 22 nominate). See Table 1 for details. These sequences clustered into 15 highly similar but distinct haplotypes. 


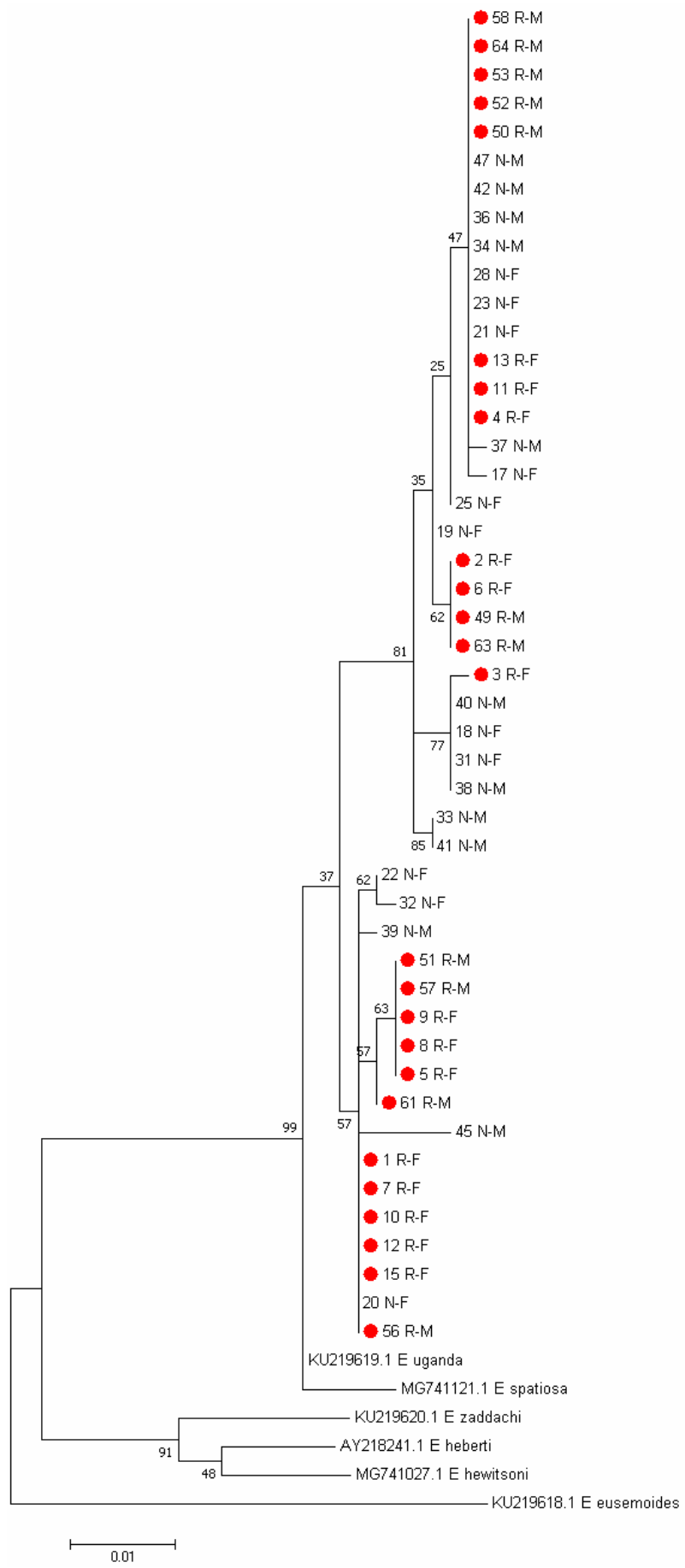

Figure 7. The phylogenetic tree. COI-based ML tree constructed using the GTR model. Red dots indicate rubromaculata form (the others are nominate form). The six outgroups are E. zaddachi (KU219620.1), E. herberti (AY218241.1), E. eusemoides (KU219618.1), E. uganda (KU219619.1), E. hewitsoni (MG741027.1) and E. spatiosa (MG741121.1). 

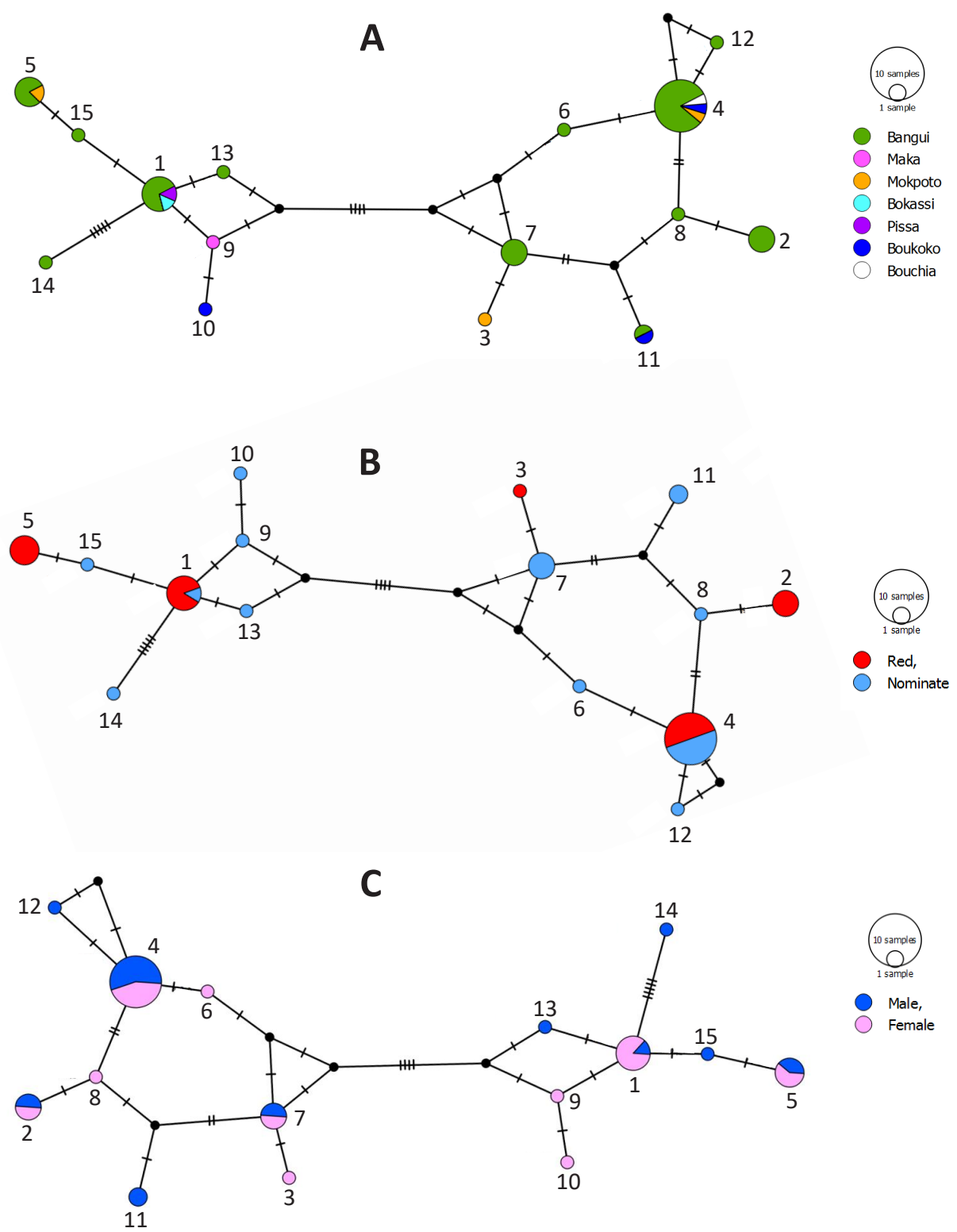

Figure 8. Median-joining networks constructed for the 15 E. eberti COI haplotypes obtained in the present study, as a function of $\mathbf{A}$ sampling location $\mathbf{B}$ wing color form, and $\mathbf{C}$ sex. Each colored circle represents a specific haplotype identified by the number beside it, and the size of each circle is proportional to the number of sequences for that haplotype. The network comprises two clusters separated by $\sim 8$ substitutions (cross-lines). Each network was generated using the software POPART.

The genetic diversity indices computed here (PVS, $\pi$, genetic distance) were similar for these two individual forms (Table 1). The ML phylogenetic tree (Figure 7) revealed that these individual forms were completely intermixed, and therefore not distinct 
Table I. Genetic diversity indices for the two E. eberti forms.

\begin{tabular}{lccccccc}
\hline Individual form & $\mathbf{n}$ & Female & Male & Variable site & PVS & $\boldsymbol{\pi}$ & Genetic distance* $^{*}$ \\
\hline rubromaculata & 25 & 14 & 11 & 12 & 0.02083 & 0.008484 & 0.009 \\
eberti & 22 & 11 & 11 & 15 & 0.02604 & 0.007456 & 0.008 \\
Total & 47 & 25 & 22 & 19 & 0.03299 & 0.008387 & 0.008 \\
\hline
\end{tabular}

n: number of sequences; PVS: proportion of variable sites; $\pi$ : nucleotide diversity; ${ }^{*}$ Genetic distances were calculated using the Tamura-Nei method (Tamura and Nei 1993).

from one another on the basis of the COI barcode. By comparison, the outgroup species used here were basal to, and distinct from, E. eberti, in agreement with the current taxonomy of the genus Euphaedra. Median-joining networks constructed to display the 15 E. eberti COI haplotypes as a function of sampling location, color morph and sex (Figure 8) further illustrated the lack of association between haplotypes and any of these three parameters. The analysis of molecular variance statistically confirmed the absence of genetic distance between the two individual forms ( $\mathrm{p}$-value $=0.464)$.

\section{Discussion}

Adults of E. eberti eberti are similar to those of E. preussi Staudinger, 1891, E. fascinata Hecq, 1984 and E. vicina Hecq, 1984, common in the investigated area and showing large color variations. However, using the broken and " $\mathrm{S}$ "-shape subapical band and some other morphological features, distinguishing $E$. eberti from these species proved easy. Euphaedra species that resemble E. eberti ab. rubromacualta, such as E. themis Hübner, 1807 or E. permixtum Butler, 1873, do not occur in the investigated area. Among the species found in the investigated area, the one most similar to ab. rubromacualta is the rare E. campaspe Felder \& Felder, 1867, which lacks the large red patch (occurring only in extremely rare cases and never with the intensity observed in E. eberti ab. rubromaculata) on the FWD, therefore making misidentification unlikely.

Among ab. rubromaculata individuals, we found several exemplars with blue color on the FWD and blue-yellow color of the HWD, among the more frequently observed yellow-green specimens. We have here confirmed that the ab. rubromaculata is present in both males and females, although no male representative of the blue form was found.

Observed dissimilarities in wing patterns between the two individual forms were not accompanied by significant differences in the genitalia, wingspan or COI haplotypes. This strongly suggests that the two individual forms reported here represent a natural variation within populations of a single species, thereby supporting current Euphaedra taxonomy (Berger 1981; Hecq 1982, 1997). Of course, the question may be raised as to whether the information contained in the COI gene sequence is sufficient to provide definitive support for the above conclusion. Although the COI gene has often been successfully used for species delimitation, nuclear DNA markers have recently gained in popularity for this purpose (Tavares and Baker 2008; Pazhenkova and Lukhtanov 2018; Maresova et al. 2019). While the existence of very distinct COI hap- 
lotypes does not always provide adequate justification for drawing species boundaries (because such COI haplotype variability is not always accompanied by equivalent variation in nuclear markers; see, for example, Pazhenkova and Lukhtanov 2018), the opposite situation (i.e., wrongly rejecting the hypothesis of a species split based on the near absence of COI sequence variability) is less likely to occur, in view of the faster evolution of animal mitochondrial DNA relative to that of its nuclear counterpart (Brown et al. 1979). However, cases of hybridization leading to mitochondrial DNA introgression have been reported (e.g., Seixas et al. 2018). It should be noted here that a recent molecular phylogeny focusing on the nymphalid subfamily Limenitidinae, based on both $\mathrm{COI}$ and several nuclear markers, indicated that the genus Euphaedra branches out into two clades, including one in which species are not all very well resolved (i.e., low bootstrap values; Dhungel and Wahlberg 2018). Although E. eberti was not included in that phylogeny, it apparently belongs to that same clade as one of the species we employed in the phylogeny reported here, E. spatiosa, belongs to that clade in the Dhungel and Wahlberg (2018) phylogeny and is shown here to be very closely related to E. eberti (Fig. 7). This close phylogenetic proximity among Euphaedra species certainly adds to the challenge of identifying genomic differences between the red and nominate forms of $E$. eberti. In future studies, a search for nuclear, genome-wide single nucleotide polymorphisms (SNPs), followed by a comparison of these SNPs between the two morphs, should be considered in an effort to further explore the present issue and identify the genomic determinants of the observed wing pattern variation in E. eberti.

Because the collection date was not recorded for every specimen, we could not evaluate the possibility that the two forms described here could be the outcome of seasonal polymorphism (polyphenism). Although we know the E. eberti ab. rubromaculata individuals from our collection were most prevalent in June and August (data not shown), pointing to possible seasonal fluctuations, our data are too sparse to draw conclusions at this stage. The only other report on seasonal occurrence is Schultze's (1920), who described a color form of E. eberti ab. rubromaculata based on a single female collected near Ubangi (DRC) in March 1911; other authors did not report exact collecting dates (Hecq 1982, 1997; Berger 1981; Van de Weghe 2010). The hypothesis of seasonal polymorphism should be examined further as this phenomenon is not exceptional in Nymphalidae, with well-known examples such as Araschnia levana Linnaeus, 1758 in Europe (Higgins and Riley 1980), and Precis octavia Cramer, 1777 and other species in Africa (Brakefield and Larsen 1984; McLeod 1984; Brakefield and Lees 1987; Morehouse et al. 2013).

Beyond seasonal polymorphism, other types of intraspecific wing pattern polymorphism have been reported for the Lepidoptera (Robertson 1971; Allen et al. 2011; Sekimura and Nijhout 2017), including geographical, sexual, and industrial polymorphism, in addition to polymorphism induced by sunlight or by temperature, etc. However, the present study did not aim at identifying the evolutionary causes of the observed wing pattern variation in E. eberti; therefore, some of the above-mentioned scenarios cannot be ruled out as the cause of the variation reported here. Moreover, why such different individual forms of this species coexist on the same territory remains unclear. 


\section{Conclusion}

The two individual forms, i.e. the nominate form E. eberti eberti, without the red patch, and the red-wing form, E. eberti ab. rubromaculata, display large differences in their wing patterns, which initially suggested they should be considered separate species. However, both forms had similar genitalic structures and shared some specific wing marks, in addition to displaying the same COI haplotype, strongly suggesting that the two morphologically distinct forms belong to the same species, E. eberti. The results of our investigation are in agreement with the current taxonomy of the genus Euphaedra. The causes of the observed variability remain unclear.

\section{Acknowledgements}

The authors thank Bangake Gilbert (RCA) for providing the study material, Reza Zahiri for technical assistance with the POPART software and Dominique Fournier (Canada) for linguistic and editorial improvements.

\section{References}

Allen CE, Zwaan BJ, Brakefield PM (2011) Evolution of sexual dimorphism in the Lepidoptera. Annual Review of Entomology 56(1): 445-464. https://doi.org/10.1146/annurevento-120709-144828

Aurivillius (1896) Ofversigt af Kongl. Vetenskaps-Akademiens Förhlhandlingar. Stockholm 53(433): 431-436.

Bandelt HJ, Forster P, Röhl A (1999) Median-joining networks for inferring intraspecific phylogenies. Molecular Biology and Evolution 16(1): 37-48. https://doi.org/10.1093/oxfordjournals.molbev.a026036

Berger L (1940) Exploration du Parc National Albert. Mission G.F. de Witte (1933-1935). Brussels (30): 1-59.

Berger LA (1981) Les Papillons du Zaïre. Weissenbruch, Brussels, 543 pp.

Brakefield PM, Larsen TB (1984) The evolutionary significance of dry and wet season forms in some tropical butterflies. Biological Journal of the Linnean Society. Linnean Society of London 22(1): 1-12. https://doi.org/10.1111/j.1095-8312.1984.tb00795.x

Brakefield PM, Lees DR (1987) Melanism in Adalia ladybirds and declining air pollution in Birmingham. Heredity 59(2): 273-277. https://doi.org/10.1038/hdy.1987.123

Brown WM, George M, Wilson AC (1979) Rapid evolution of animal mitochondrial DNA. Proceedings of the National Academy of Sciences of the United States of America 76(4): 1967-1971. https://doi.org/10.1073/pnas.76.4.1967

Dhungel B, Wahlberg N (2018) Molecular systematics of the subfamily Limenitidinae (Lepidoptera: Nymphalidae). PeerJ 6: e4311. https://doi.org/10.7717/peerj.4311 
Folmer O, Black M, Hoeg W, Lutz R, Vrijenhoek R (1994) DNA primers for amplification of mitochondrial Cytochrome $\mathrm{C}$ oxidase subunit I from diverse metazoan invertebrates. Molecular Marine Biology and Biotechnology 3(5): 294-299. https://pdfs.semanticscholar.or g/943d/38b9d96f8222e883604822bcafb7930ca6da.pdf

Hecq J (1976) Essai de classification du genre Euphaedra Hbn. Lambillionea 86(5-6): 38-49.

Hecq J (1982) Etude des Euphaedra (Nymph. Afric.). Note no. 22 (suite) Monographie du groupe themis Hubn. (Sous - genre Euphaedrana Hecq). Lambillionea 82(5-6): 44-48.

Hecq J (1997) Euphaedra. Union des Entomologistes Belges, Tervuren, 117 pp.

Hecq J (2008) Nouveaux Euphaedra du Bas-Congo (RDC) (Lepidoptera Nymphalidae). Lambillionea 108(1): 109-110.

Higgins LG, Riley ND (1980) A Field Guide to the Butterflies of Britain and Europe. Collins, London, $384 \mathrm{pp}$.

Kumar S, Stecher G, Tamura K (2016) MEGA7: Molecular Evolutionary Genetics Analysis version 7.0 for Bigger Datasets. Molecular Biology and Evolution 33(7): 1870-1874. https://doi.org/10.1093/molbev/msw054

Larsen TB (2005) Butterflies of West Africa. Apollo Books, Stenstrup, 900 pp.

Maresova J, Habel JCH, Neve G, Sielezniew M, Bartonova A, Kostro-Ambroziak A, Fric ZF (2019) Cross-continental phylogeography of two Holarctic Nymphalid butterflies, Boloria eunomia and Boloria selene. PLoS One 14(3): e0214483. https://doi.org/10.1371/journal. pone. 0214483

McLeod L (1984) Seasonal polyphenism in African Precis butterflies. In: Vane-Wright RI, Ackery PR (Eds) The Biology of Butterfies, Symposium of the Royal Entomological Society of London, 11: 313-315.

Morehouse NI, Mandon N, Christides JP, Body M, Bimbard G, Casas J (2013) Seasonal selection and resource dynamics in a seasonally polyphenic butterfly. Journal of Evolutionary Biology 26(1): 175-185. https://doi.org/10.1111/jeb.12051d

Pazhenkova EA, Lukhtanov VA (2018) Nuclear genes (but not mitochondrial DNA barcodes) reveal real species: Evidence from the Brenthis fritillary butterflies (Lepidoptera, Nymphalidae). Journal of Zoological Systematics and Evolutionary Research 57: 1-16. https://doi. org/10.1111/jzs.12252

Pyrcz TW, Lorenc J, Knoop DP (2011) New species of Euphaedra Hübner of the ceres group from southwestern Nigeria - with new evidence from female genital morphology (Lepidoptera: Nymphalidae: Limenitidinae). Genus 22(4): 621-638. http://www.cep.uj.edu. pl/documents/139445489/141836086/2011_08_pyrcz_lorenc_euphaedra_nigeria. pdf/034a0c71-27f9-41b7-bdfe-fb39358c7b90

Pyrcz TW, Warren-Gash H, Lorenc-Brudecka J, Knoop DP, Oremans P, Sáfián S (2013) Taxonomy and distribution pattern of the African rain forest butterfly genus Euphaedra Hübner sensu stricto with the description of three new subspecies of Euphaedra cyparissa (Cramer) and one of E. sarcoptera (Butler) (Lepidoptera, Nymphalidae, Limenitidinae, Adoliadini). ZooKeys 10(298): 1-37. https://doi.org/10.3897/zookeys.298.4894

Robertson R (1971) Lepidoptera Genetics. Pergamon Press, Oxford, 457 pp.

Robinson GS (1976) The preparation of slides of Lepidoptera genitalia with special reference to the Microlepidoptera. Entomologist's Gazette 27: 127-132. 
Schultze A (1920) Lepidoptera. 11. Teil. Ergebnisse. der Zweiten Deutschen Zentral Afrika Expedition. 2910-11. Vol. 1, Part 14: 639-837.

Seixas FA, Boursot P, Melo-Ferreira J (2018) The genomic impact of historical hybridization with massive mitochondrial DNA introgression. Genome Biology 19: 91. https://doi. org/10.1186/s13059-018-1471-8

Sekimura T, Nijhout HF (2017) Diversity and Evolution of Butterfly Wing Patterns: An Integrative Approach. Springer, 321 pp. https://doi.org/10.1007/978-981-10-4956-9

Tamura K, Nei M (1993) Estimation of the number of nucleotide substitutions in the control region of mitochondrial DNA in humans and chimpanzees. Molecular Biology and Evolution 10(3): 512-526. https://doi.org/10.1093/oxfordjournals.molbev.a040023

Tavares ES, Baker AJ (2008) Single mitochondrial gene barcodes reliably identify sister-species in diverse clades of birds. BMC Evolutionary Biology 8: 81-95. https://doi.org/10.1111/ j.1755-0998.2010.02875.x

Van de Weghe GR (2010) Les papillons du Gabon. Libreville, Wildlife Conservation Society, 424 pp. 